Ахмедова 3.M. Выражение концепта принадлежности в английском языке формой абсолютного родительного падежа и его эквиваленты в азербайджанском языке

УДК 811:81.316

DOI: 10.21779/2542-0313-2017-32-2-53-61

\title{
3.М. Ахмедова
}

\section{Выражение концепта принадлежности в английском языке формой абсолютного родительного падежа и его эквиваленты в азербайджанском языке}

Бакинский государственный университет; Азербайджан, Баку, AZ1148, ул. 3. Халилова, 23; zahrahmadova@gmail.com

Азербайджанский и английский языки принадлежат к различным языковым семьям. Поэтому принадлежность выражается в каждом языке особыми средствами. Некоторые особенности, являющиеся общими для всех языков, рассматриваются как универсалии, например личные местоимения (притяжательная конструкция) и окончания падежей.

В данной статье анализируется форма абсолютного родительного падежа, являющаяся одним из средств выражения концепта принадлежности в английском языке, и исследуются эквиваленты этой формы в азербайджанском языке. Научная новизна статьи состоит в том, что хотя, форма абсолютного родительного падежа в английском языке привлекалась в определённой степени к исследованию, до сих пор не были рассмотрены эквиваленты этой формы в азербайджанском языке, они не стали объектами типологического исследования, не были выявлены схожие и отличительные особенности, присущие этим эквивалентам. С этой точки зрения данная статья имеет определенную значимость как один из первых шагов в области сравнительного исследования азербайджанского и английского языков.

Ключевые слова: конщепт принадлежности, абсолютный родительный падеж, маркированный падеж, посессум, посессор.

Хотя проблема категориального содержания принадлежности и рассматривалась до сих пор в типологическом, сравнительно-историческом, структурном и функциональном аспектах, все же она не утратила своей актуальности в принципах современной когнитивной научной парадигмы. В различных языках отношения принадлежности или конкретизируются, или представляются лексическим, синтаксическим и морфологическим способами, или же обобщаются определенными синтаксическими конструкциями. На этом основании языковеды для выражения отношений принадлежности предлагают такие различные, традиционные термины, как принадлежность, посессивность, обладание и нетрадиционное понятие - ассоциативность. У понятия принадлежность нет конкретного определения, поэтому его наличие ставится порою под сомнение, а это приводит к ограничению значения понятия посессивность до обладания.

Имеются узкое и широкое толкования термина принадлежность [16, с. 202; 14, c. $577 ; 15$, с. 100]. Вообще толкование отношений принадлежности предполагает присутствие двух участников этих отношений - субъекта и объекта принадлежности. Часть языковедов в качестве субъекта отношений принадлежности представляет только человека. Вторая группа языковедов считает, что субъектом принадлежности должны быть все живые существа. А третья группа языковедов утверждает, что субъектами принадлежности могут быть и неживые предметы [14, с. 152; 24, с. 1-25]. Мнения языковедов по трактовке объекта принадлежности также различаются. В более узком значении объекты принадлежности - это предметы реальной действительности. В этом случае 
Ахмедова 3.M. Выражение концепта принадлежности в английском языке формой абсолютного родительного падежа и его эквиваленты в азербайджанском языке

субъектом принадлежности является человек, а отношения принадлежности направлены к личностным отношениям. Некоторые языковеды в понятие объект включают не только предметы или существительные, определяющие личность, но и события, происходящие с субъектом, его качества, существительные с различными абстрактными оттенками [16, с. 203; 14, с. 152]. Мы принимаем термин принадлежность, воспринимаемый в широком смысле.

Именно поэтому концепт принадлежности изоморфен языку в более важном аспекте. В термин принадлежность входят такие лингвистические понятия, которые дают нам возможность увидеть языковую карту носителей определенного языка. Единицы и синтаксические конструкции, носящие содержание принадлежности, отражают особенности связей, существующих за пределами языка, а также отражающихся в мышлении. Концепт принадлежности играет немалую роль в выполнении коммуникативной функции в предложении. Он играет значительную роль в смысловой организации высказывания, а средства его выражения - в объединении элементов внутри текста. Можно отметить, что концепт принадлежности играет большую роль и в словообразовании. В выражении этого концепта морфология, а также синтаксис выступают как объекты, и он реализуется через непосредственное участие категории падежа. Концепт принадлежности тесно связан с анафорической и дейктической структурами языка.

К понятию принадлежность, считающемуся в литературе по языкознанию «сложным событием», нет единого подхода. С одной стороны, его связывают с понятием обладание, с другой - оно как более широкое понятие охватывает определенное отношение между субстанциями принадлежности, а иногда также отношения между предметом и признаком.

Исследователи признают, что понятие обладание связано с понятием человек (субъект). Поэтому, употребляя слово принадлежность, следует иметь в виду специфические отношения, отличающие две субстанции (с условием знания того, что одна из этих субстанций живая). Иными словами, обладателем определенной субстанции может быть только живое существо - человек. С точки зрения логики в сравнении с отношениями между человеком и предметом, отношения между вещами и предметами являются второстепенными, производными [13, с. 171-174].

Следует отметить, что необходимо в определенной степени различать понятия принадлежность и обладание. Понятие принадлежность отражает принадлежность определенного предмета определенному субъекту, т. е. является особенностью обладания субъекта. Определенный субъект может быть обладателем того или иного предмета. Понятия принадлежность и обладание являются близкими, но не однородными, т. е. два различных понятия, связанные друг с другом в зависимости от цели коммуникации.

Сущность концепта принадлежности можно более ясно увидеть при исследовании системы падежа. Ее можно увидеть в основном на примере родительного падежа.

Азербайджанский и английский языки, привлекаемые нами к исследованию с точки зрения генеалогии и морфологической структуры, принадлежат к различным языковым семьям. Поэтому в выражении концепта принадлежности между ними проявляются схожие и отличающиеся особенности. Естественно, что концепт принадлежности подчиняется особенностям, определенным закономерностям того или иного языка. В каждом языке принадлежность выражается особыми средствами. Некоторые общие особенности, свойственные всем языкам, можно рассматривать как универсалии: например, притяжательные местоимения (притяжательные конструкции) и падежные окончания. Концепция принадлежности выражается в языке несколькими способами. 
Ахмедова 3.M. Выражение концепта принадлежности в английском языке формой абсолютного родительного падежа и его эквиваленты в азербайджанском языке

Одним из таких методов является абсолютная форма родительного падежа в английском языке. В данной статье на примерах азербайджанского и английского языков исследуются своеобразные особенности выражения концепта принадлежности формой абсолютного родительного падежа.

«Саксонский генитив», отражающий посессивные отношения и отличающийся использованием апострофа (boy's, boys'), является единственным окончанием существительных, сохранившимся из древнеанглийского языка или с англосаксонского периода («S-genitive» известен также как «саксонский генитив») [31, с. 291].

Основным значением единственного маркированного родительного падежа является принадлежность. Как в азербайджанском, так и в английском языке в синтетическом выражении понятия «принадлежность» исключительное значение имеют окончания родительного падежа. Среди сравниваемых языков только в азербайджанском языке в выражении понятия «принадлежность» участвуют аффиксы родительного падежа и принадлежности. А в английском языке в выражении концепта принадлежности участвуют окончания родительного падежа.

Родительный падеж является способом выражения синтаксем принадлежности. Синтаксема принадлежности, отражающаяся в родительном падеже существительного, широко описывается в английском языке. Это обстоятельство обусловлено тем, что значение принадлежности является основным смыслом родительного падежа. Лексическую базу данной синтаксемы в основном составляют одушевленные, а также неодушевленные существительные [9, с. 35].

Что такое посессивность и как она выражается в языке? Когда мы намерены привести определенный пример в родительном падеже, приходит на ум не Jane's character («характер Джейн»), a Jack's pen («ручка Джека»). Несмотря на то, что в обоих случаях (примерах) родительный падеж выражен синтетическим методом, значение генитива в первом примере (случае) нефункциональное. «Посессивное» (принадлежное) значение генитива является единственно продуктивным [27, с. 207-228; 29, с. 159]. Мы полностью согласны с этой мыслью. Этот анализ дает нам возможность предположить, что все значения генитива не сосредоточены в мозгу говорящего равномерно по сравнению с другими, т. е. некоторые значения более функциональны.

В некоторых случаях существительное, к которому присоединяется окончание родительного падежа, пишется без последующего существительного, т. е. это существительное употребляется не в составе конструкции, а самостоятельно. Эта форма родительного падежа исследуется под названиями «абсолютный родительный падеж», «самостоятельный родительный падеж», «эллиптический генитив», «анафорический / катафорический родительный падеж».

Отметим, что среди исследователей-языковедов нет единого мнения об употреблении генитива без посессума. А. Розенбах и Дж. Мейер-Миклестад отмечали, что термин elliptic-genitive (эллиптический генитив), восстанавливаемый лингвистическим контекстом, может быть общепринятым во всех случаях, используемых без участия посессума [30, с. 32; 28, с. 58]. Некоторые авторы считают употребление существительного в родительном падеже без основного слова «самостоятельным родительным падежом» [23, с. 259; 22, с. 35] или «самостоятельным генитивом» [26, с. 329; 18, с. 63; 19, c. 296], называя их «анафорическими». Учитывая то, что в зависимости от лингвистического контекста на основании другого определяемого слова, представленного в самом предложении, можно восстановить посессум и в этих примерах генитив не всегда

Вестник Дагестанского государственного университета. 
Ахмедова 3.M. Выражение концепта принадлежности в английском языке формой абсолютного родительного падежа и его эквиваленты в азербайджанском языке

может сохранить свою самостоятельность, можем отметить, что мнения О. Есперсена и Г. Борштшаненко более соответствуют истине [25, с. 12-15; 20, с. 41-42].

Г. Борштшаненко делила анафорический родительный падеж на две части:

а) перед посессумом и после него. Их можно восстановить на основе представленного контекста [20, с. 41]. Например:

(I) Jennifer's is the only face I recognize here (i. e. Jennifer's face) - Единственным человеком, которого я знаю, является Дженифер.

(II) He has a devotion to work like his father's (i. e. father's devotion) - Он также привязан к работе, как отец.

That isn't my diary - it's Luke's (Luke's diary) - Тот дневник не мой - он Люки (дневник Люка) [21, с. 214];

б) посессум неанафорического типа. Он не даётся в ранее представленном контексте [20, с. 42]. Например: He crossed Fight Avenue at St. Patrick's and recalled walking through the church once-such a tourist thing to do and watching Lois light a candle (Rick Hamlin) - (Он пересек Файт-авеню у площади Св. Патрика и вспомнил, как когда-то проходил через церковную площадь, - совсем, как делают это туристы, и наблюдал за тем, как Луис зажигал свечи) [33].

Дж. Аллен отмечал, что в древнеанглийском языке встречаются два вида: анафорический и катафорический;

a) (1) na purh his agene mihte, ah purh godes "not through his own power, but through God's" - Не своим, а Божьим желанием... [17, с. 352];

б) hit is eal Godes "It is all God's" - Это полностью принадлежит Богу [17, с. 351].

Существительное в родительном падеже без основного слова употребляется:

а) как эквивалент словосочетания, в котором для недопущения повтора опускается второй компонент. Например:

He was whistling note like a bird's (i. e. like a bird's note) - Это был голос, похожий на птичий.

If Annete didn't respect his feelings, she might think of Fleur's (i. e. Fleur's feeling) (J. Galsworthy) - Хотя Аннет не уважала его (парня) чувства, она должна была учитывать чувства Флёра [11, с. 46].

б) также и с существительными, означающими «торговлю», «отношения», «здания», «магазин». Это находит своё отражение в основном в приставках. Например:

He has asked her to choose a restaurant and she suggested Scott's - Я попросил его выбрать ресторан, и он посоветовал мне «Скот» (ресторан «Скот»).

They were married at St. Paul's - Они обвенчались в церкви Св. Павла.

Профессор В. Ильиш в связи с обретением нового, пространственного смысла слов в родительном падеже называл его «деривационным окончанием»: at the baker's, at St. Paul's, at Timothy's, at my brother's [10, c. 67-68].

В конструкциях типа St. Paul's, baker's отношения личностной принадлежности не наблюдаются. В этих конструкциях важным является не значение принадлежности, а концепт пространства. В них окончание 's вместе с вышеупомянутыми префиксами более ярко демонстрирует концепт пространства и времени.

Концепт принадлежности можно наблюдать в тюркских языках, в том числе и азербайджанском языке. Как отмечал Н. Дмитриев, «в тюркской грамматике принадлежность является одной из важнейших категорий» [12, с. 23]. Через концепт принадлежности выражаются отношения между людьми и предметами. 
Ахмедова 3.M. Выражение концепта принадлежности в английском языке формой абсолютного родительного падежа и его эквиваленты в азербайджанском языке

Концепт принадлежности находит своё отражение в родительном падеже, с помощью которого выражаются различные смысловые оттенки принадлежности.

В азербайджанском языке в выражении понятия «принадлежность» исключительное значение имеет окончание родительного падежа. В английском и азербайджанском языках родительный падеж занимает второе место среди падежей. В результате аналитического сравнения способов выражения в английском и азербайджанском языках мы пришли к такому выводу: аффиксы родительного падежа и принадлежности участвуют только в азербайджанском языке, а в английском - окончания родительного падежа.

Наиболее важным грамматическим признаком родительного падежа является его падежный суффикс. Данный падеж выражает содержание собственности и принадлежности. Так же, как и в английском языке, в азербайджанском языке родительный падеж может употребляться без существительного - посессор не зависит от посессума (обладаемого). Концепция принадлежности, выражаемая в английском языке с помощью абсолютного родительного падежа, передается в азербайджанском языке тремя формами:

I. Слово в родительном падеже может использоваться и без зависимого слова. Это возможно в рамках определенного контекста, выражаясь точнее, в ответе на поставленный вопрос. Например: ся?

Bir açıq de görüm, kimin xatasına düşmüsən? - Скажи мне прямо, во что ты ввязал-

- Kimin olacaq, dostun Şirzadın! (İbrahimov M.) - Ну, как обычно, проблемы твоего друга Ширзада!

II. М. Гусейнзаде пишет об этом так: «Родительный падеж может быть отдельным членом предложения; особенно может быть сказуемым в предложении, если принимает окончание сказуемого. Например, в предложении İndi söz cavanlartndır - А теперь слово предоставляется молодым - слово cavanlartn (молодым) является сказуемым в родительном падеже. В другом случае родительный падеж, несмотря на выражение определённости, становится соответствующим сложным членом предложения вместе с последующим словом» [3, с. 48].

Отметим, что это возможно при помощи инверсии. Определённый родительный падеж, используемый в форме сказуемого, выраженного существительным, употребляется отдельно в конце предложения. Это считается сравнительно независимым состоянием определённого родительного падежа. Например: Bu kitab talabələrindir - Это книга студентов [1, с. 35].

Несмотря на то, что этот вопрос не изучен в научной литературе, мы встречаем краткую информацию, связанную с ним в книге Ю. Сеидова: «Родительный падеж существительного также употребляется в роли сказуемого, и в это время словно теряет «оковы», переходит в активную непосредственную связь с членами предложения. Например: Kitablar həmin taləbənindir - Эти книги того самого ученика.

В этом предложении сказуемое, выраженное существительным в родительном падеже, согласуется с подлежащим. Выражение сказуемого существительным в родительном падеже не так уж часто применяется. В сравнении с другими предложениями, в которых сказуемое выражено существительным, эти предложения отличаются ограниченным количеством слов».

Самостоятельное выступление существительного согласующегося с подлежащим предложения в родительном падеже, в качестве сказуемого, выраженного существительным, является характерным явлением для обоих языков. Отметим, что приведённые примеры в действительности являются словосочетаниями, употребляемыми в со- 
Ахмедова 3.M. Выражение концепта принадлежности в английском языке формой абсолютного родительного падежа и его эквиваленты в азербайджанском языке

кращённой форме. При восстановлении сокращённого слова в этих словосочетаниях становится ясно, что предикативный суффикс добавлен не к существительному в родительном падеже, а к существительному, находящемуся в составе конструкции слова в именительном падеже с притяжательным аффиксом: Bu məktub anamındır - Это письмо моей матери. $\rightarrow$ Bu məktub anamın məktubudur - Это письмо является письмом моей матери.

III. Одним из способов, широко применяемых в азербайджанском языке и отличающихся своеобразными особенностями в выражении концепта принадлежности, является присоединение элемента -ki к существительному в родительном падеже (или же к форме родительного падежа личного местоимения). Данный метод выражения понятия принадлежности в речи называется синтетическим [6, с.89].

М. Гусейнзаде называл существительные и местоимения, употребляемые с аффиксом -ki, «гражданским земиром» (mülki zәmir) (земир - арабское слово, означающее в старой грамматике название местоимения): mənimki, özümkü, Әhmədinki (мой, свой, Ахмеда) [8, с. 50].

С. Джафаров пишет об этом: «Как видно, аффиксы -inki/-inki/-unku/-ünkü можно добавить не только к личным местоимениям, но и ко всем существительным. Вовторых, этот аффикс, который добавляется к слову, создаёт в нём (и в существительных и личных местоимениях) единый лексический смысл, смысл притяжательности и настаивания; например, sizinki, bağınki, evinki (ваш, сада, дома) и др.» [2, с. 80].

После аффиксов родительного падежа к личным местоимениям добавляется аффикс -ki, и образуется категория принадлежности. Например: mənimki, səninki, onunku, bizimki, sizinki, onlarınki (мой, твой, его / ее, наш, ваш, их). Здесь слова mənim, sənin, onun, bizim, sizin, onlarin (мой, твой, его / еe, наш, ваш, их) указывают на первый компонент категории принадлежности - обладателя, владельца, а аффикс -ki4 - на второй компонент - принадлежащую сторону.

Хотя в составе соединений, созданных аффиксом принадлежности -ki, имеется одно слово, в его содержании осознаётся и объект, и субъект [4, с. $63 ; 5$, с. 215]. В категории принадлежности, выраженной таким способом, аффикс -ki заменяет принадлежащего человека, предмет, принадлежащую категорию [5, с. 215]. То же самое можно сказать и о присоединении элемента -ki4 к существительным в родительном падеже. Например: Mənimkilor təndir qoyur, sən yüyür! Bahar enişə doğru qaçdl. Mürsəl qoruqçunun qorxusundan öz quzularını ayırırdı (Mir Cəlal) - Мои печку топят, ты беги! Бахар побежала вниз. Мурсал, испугавшись караульщика, отделил своих ягнят.

Элемент -ki4, выражая ранее упомянутое существительное, употребляется вместо него. Особенности единиц с элементом -ki4:

1) Единицы с элементом -ki4 не могут употребляться самостоятельно, изолированно; для этого необходимым является наличие соответствующего контекста (перед предложением, в котором употребляется эта единица, или после такого предложения). В своей монографии «Сложные существительные в современном английском и азербайджанском языках» Н. Набиева справедливо отмечает, что единицы с элементом -ki4 похожи на эллиптические предложения и на анафорически употребляемые местоимения (особенно на личные местоимения) [7, с. 96].

2) Единицы с элементом -ki4, содержащие в себе три понятия («человек», «принадлежность» и «принадлежащий предмет»), самостоятельно отражают концепт принадлежности. Bu papaq mənim, təzəsi isə Həsəninkidir - Эта шапка моя, а новая Гасана / принадлежит Гасану. 
Следует добавить, что обладатель - субъект, выраженный существительным в родительном падеже (или формой родительного падежа личного местоимения), заранее известен говорящему, т.е. здесь основную роль играют знания говорящего и слушающего о действительности. Знания говорящего и слушающего становятся очевидными из языкового контекста.

В своей статье, посвящённой аффиксу $-k i 4$, С. Ширинов, соглашаясь с мнением, что «в отличие от других аффиксов, служащих образованию прилагательного, аффикс -ki4 употребляется после окончаний родительного и творительного падежей, отмечает, что простые, производные и сложные существительные принимают аффикс -ki4 после склонения (родительный, дательный падежи). Например: Səliminki, evinki - Салима, дома и др. [32].

Учитывая всё вышесказанное о форме абсолютного родительного падежа в выражении «концепта принадлежности» в английском языке и его эквивалентах в азербайджанском языке, можно прийти к следующим типологическим выводам:

1) В обоих языках при выражении концепта принадлежности исключительное значение имеет окончание родительного падежа.

2) В азербайджанском языке невозможно использовать абсолютный родительный падеж и его эквиваленты самостоятельно, изолированно; необходимым условием для их использования является наличие соответствующего контекста (перед предложением, в котором употребляется эта единица, или после такого предложения).

3) При выражении концепта принадлежности с помощью абсолютного родительного падежа и его эквивалента в азербайджанском языке родительный падеж самостоятельно становится простым членом предложения, а в других случаях родительный падеж вместе с последующим словом становится соответствующим сложным членом предложения.

4) В собственных существительных, в существительных торгового и прочего содержания, в т. ч. в конструкциях, означающих «здание» или «магазин» (типа St. Paul's, baker's), отношения личной принадлежности не наблюдаются. В этих конструкциях важным является не значение принадлежности, а концепт принадлежности. В них окончание 's вместе с приставками более ярко демонстрирует концепт пространства. Такие соединения в азербайджанском языке не наблюдаются;

5) В азербайджанском языке, это понятие можно использовать не только с помощью окончания родительного падежа, но и посредством употребления существительного в родительном падеже (или же формой родительного падежа личного местоимения) вместе с единицами с элементом -ki4.

\section{Литература}

1. Abdullayeva G. Müasir Azərbaycan Dili. II hissə (morfologiya, sintaksis). - Bak1, 2013. - 308 s. (на азерб.)

2. Cəfərov $S$. Azərbaycan dilində söz yaradıcılığı. Azərbaycan Universiteti nəşriyyatı. - Bak1, 1960. - 204 s. (на азерб.)

3. Hüseynzadə M. Müasir Azərbaycan dili. III hissə. - Bak1: Şərb-Qərb, 2007. - 280 s. (на азерб.)

4. Hüseynzadə M. Müasir Azərbaycan dilində təktərkibli və mürəkkəb təyini söz birləşmələri. - Bakı: ADU nəşriyyatı, 1957. - 234 s. (на азерб.)

5. Xalilov B. Müasir Azərbaycan dilinin morfologiyas1. I hissə. - Bak1: Nurlan, 2007. - 280 s. (на азерб.) 
6. Kazımov Q. Müasir Azərbaycan dili. Morfologiya. - Bak1, 2010. - 400 s. (на азерб.)

7. Nəbiyeva N. Müasir ingilis və Azərbaycan dilində mürəkkəb isimlər. - Bakı, 2005. - 128 s. (на азерб.)

8. Seyidov Y. Azərbaycan dilinin qrammatikas1. Morfologiya. - Bak1: Bak1 Univ. Nəşr., 2006. - 371 s. (на азерб.)

9. Акбулатова A.M. Родительный падеж в структуре предложения современного английского языка: дис. ... канд. филол. н. - Л., 1984. - 196 с.

10. Афанасьев П.А. Теоретическая грамматика английскою языка: учебное пособие. - Таганрог, Эсперо, 2001. - 128 с.

11. Бархударов Л.С., Штелинг Д.А. Грамматика английского языка. - М.: Высшая школа, 1973. - $423 \mathrm{c}$.

12. Дмитриев Н.К. Категория принадлежности // Исследования по сравнительной грамматике тюркских языков. Морфология, ч. 2. - М.-Л., 1956. - С. 22-37.

13. Иванова Т.А. О содержании категории притяжательности // Вестник ЛУ. История, язык, литература. - 1975. - Вып. 2, № 8. - С. 171-174.

14. Селиверстова О.Н. Контрастивная синтаксическая семантика. Опыт описания // Труды по семантике. - М., 2004. - 152 с.

15. Теория функциональной грамматики. Локативность. Бытийность. Посессивность. Обусловленность / отв. ред. А.В. Бондарко. - СПб.: Наука, 1996. - 100 с.

16. Цейтлин С.Н. Семантическая категория посессивности в русском языке и ее освоение ребёнком // Семантические категории в детской речи: сборник. - СПб.: Нестор-история, 2007. - 436 с.

17. Allen C.L. A Note on 'Elliptical', 'Absolute', and 'Independent' Genitives in Earlier English // English Language and Linguistics. - 2004. - Vol. 8, Issue 2. - P. 351-354.

18. Altenberg B. The Genitive v. the of-Construction: A Study of Syntactic Variation in 17th Century English. - Lund: CWK Gleerup, 1982.

19. Biber D., Johansson S., Leech G., Conrad S. and Finegan E. Longman Grammar of Spoken and Written English. - Harlow: Longman, 2006.

20. Borshtshanenko G. The Form and Function of the Genitive in late medieval London English. - University of Oslo, 2008. - P. 182.

21. Eastwood J. Oxford Guide to English grammar. - Oxford University Press. - 1994. - P. 446.

22. Ganshina M.A., Vasilevskyaya N.M. English Grammar. - Macmillan Education, 2008. - 240 p.

23. Gordon E.M., Krylova I.P. A grammar of present-day English. - M.: Высшая школа, 1986. - Р. 430.

24. Herslund M., Baron I. Introduction: Dimensions of possession // Dimensions of possession. - Amsterdam-Philadelphia: John Benjamins Publishing Company, 1984. - P. 125.

25. Jespersen O. A Modern English Grammar on Historical Principles, Part III: Syntax, Vol. II. - Copenhagen: Einar Munksgaard, 1949. - P. 12-15.

26. Quirk R., Greenbaum S., Leech G. and Svartvik J. A Comprehensive Grammar of the English Language. - London: Longman, 1985.

27. Merlier Octave. Le remplacement du datif par le genitif en grec moderne. Bulletin de Correspondence Hellenique. - Athens: Ecole Frangaise d'Athenes, 1931. - P. 207-228. 
28. Meyer-Myklestad J. An Advanced English Grammar for Students and Teachers. Oslo: Universitetsforlaget, 1968.

29. Nikiforidou Kiki. The meanings of the genitive: A case study in semantic structure and semantic change // Cognitive Linguistics. - 1991. - Vol. 2, Issue 2. - P. 149-205.

30. Rosenbach A. Genitive Variation in English: Conceptual Factors in Synchronic and Diachronic Studies. - Berlin: Mouton de Gruyter, 2002.

31. Szmrecsanyi B., Hinrichs L. other. The Dynamics of Linguistic Variation: Corpus evidence on English past and present / Ed. by Terttu Nevalainen, Irma Taavitsainen, Päivi Pahta and Minna Korhonen [Studies in Language Variation 2]. - Helsinki, 2008. - 352 p

32. http//yenisumqayit.az/3838-sumqayitli-dilchi-metodistin-yazisi-ki-shekilchisi-veonun-ishtiraki.html (29.10.2016).

33. https://www.thoughtco.com/independent-genitive-possession1691158 (15.03.2017).

Поступила в редакиию 30 июля 2017 г.

UDC 811:81.316

DOI: 10.21779/2542-0313- 2017-32-2-53-61

\section{The expression of possession concept in English by means of the absolute form of the genitive case and its equivalents in the Azerbaijani language}

\section{Z.M. Akhmedova}

Baku State University; Azerbaijan, AZ1148, Baku, Z. Khalilova st., 23; zahrahmadova@gmail.com

The Azerbaijani and English languages, drawn to the study, belong to different language families from the point of view of morphological and genealogical structure. Therefore, the expression of the concept of possession reveals some similar and distinctive features between these languages. Possession is expressed by special means in every language. The essence of the concept of possession can be more clearly seen in the field of the case system, which is mainly embodied in the genitive case. Some features that are common to all languages are considered to be universal, for instance, personal pronouns (possessive constructions) and possessive case endings.

This article deals with the absolute form of the genitive case, one of the means of expressing the concept of possession in the English language, and its equivalents in the Azerbaijani language. The scientific novelty of the article is that although the absolute form of the genitive case has been studied in the English language to a certain extent, the equivalents of this form in the Azerbaijani language have not become the objects of typological research so far; similar and distinctive features inherent in these equivalents have not been compared. From this point of view, this article has an important significance and can be considered one of the first steps in the field of comparative study of the Azerbaijani and English languages.

Keywords: consept of possession, absolute genitive case, marked case, possessum, possessor.

Received 30 July, 2017 